\title{
Effect of Vitamin D on Bone Mineral Mass in Normal Subjects and in Epileptic Patients on Anticonvulsants: A Controlled Therapeutic Trial
}

\section{Summary}

The bone mineral mass was estimated by photon absorptiometry in 23 epileptic patients on long-term treatment with phenytoin and in 20 normal subjects before and during treatment with vitamin $D$ or placebo.

Initially, subnormal values of bone mineral mass were found in the epileptic patients. The group of epileptic patients treated with vitamin $D$ showed a significant increase in bone mineral mass. The group of epileptic patients treated with placebo and the normal subjects treated with vitamin $D$ or placebo showed no change in bone mineral mass.

\section{Introduction}

Manifest biochemical osteomalacia (with hypocalcaemia and raised serum alkaline phosphatase) in epileptic patients on longterm treatment with anticonvulsant drugs has been reported several times in the past four years (Schmid, 1967; Kruse, 1968; Dent et al., 1970; Richens and Rowe, 1970; Hunter et al., 1971).

On average, patients without biochemically manifest osteomalacia have a decreased bone mineral mass (Berger and Munde, 1970; Linde et al., 1971; Christiansen et al., 1972), and such patients show an increase in bone mineral mass during treatment with vitamin D (Christiansen et al., 1972).

The effect on bone mineral mass of normal persons by small doses of vitamin $\mathrm{D}$ is unknown. We report a controlled therapeutic trial on the effect of the treatment in normal subjects and in epileptic patients on anticonvulsants.

\section{Patients and Methods}

Altogether 23 epileptic patients and 20 normal subjects were studied. The epileptic patients were 12 women and 11 men aged 23 to 56 years (mean 38 years). They were all fully able to work and attended the epilepsy clinic at Glostrup Hospital at regular intervals. Long-term treatment with phenytoin had been instituted one to 13 years (mean seven years) previously. During this investigation the mean dose was $5.1 \mathrm{mg}$ (range 3.3 to $6.6 \mathrm{mg}$ ) per $\mathrm{kg}$ body weight, and on this regimen the serum levels (Larsen, 1971) averaged $7 \mathrm{mg} / \mathrm{l}$. (range 2 to $14 \mathrm{mg} / 1$.) The normal subjects were 10 women and 10 men from the staff of the department aged 21 to 33 years (mean 28 years).

\section{Glostrup Hospital, 2600 Glostrup, Denmark}

CLAUS CHRISTIANSEN, CAND. MED., Assistant Physician, Department of Clinical Physiology

MOGENS LUND, M.D., Physician-in-Chief, Department of Neurology

Aalborg Sygehus Syd, 9000 Aalborg, Denmark

PAUL RØDBRO, M.D., Physician-in-Chief, Department of Clinical Physiology
The bone mineral mass was determined by direct photon absorptiometry on both forearms. Cameron et al. (1968) showed a direct relation between the absorption of photons from ${ }^{125}$ I and the bone mineral mass. In our modified version of the method (Jensen et al., 1972; Christiansen and Rødbro, 1973) the bone mineral mass is expressed in arbitrary units as a mean value of six scans from each forearm.

The bone mineral mass was measured and termed "initial value" $-100 \%$ at time $t_{0}$. This measurement was compared in each case with the values in a group of normal subjects (Christiansen and Rodbro, 1973) matched for age and sex (see chart). The epileptic patients and the normal subjects were then allocated at random to two groups. The first group was treated with calcium lactate ( $390 \mathrm{mg} / \mathrm{ca}$ daily) and vitamin D (2,000 IU daily), both drugs given by mouth, and the second group was treated with calcium lactate ( $390 \mathrm{mg} / \mathrm{ca}$ daily) and placebo. Bone mineral mass was measured one month after the treatment was started, $t_{1}$, and expressed as a percentage of the initial value.

The therapeutic trial was conducted over the months October to November 1972, and Student's $t$ test for pair differences was used to evaluate the effect of treatment.
BONE MINERAL MASS BEFORE TREATMENT
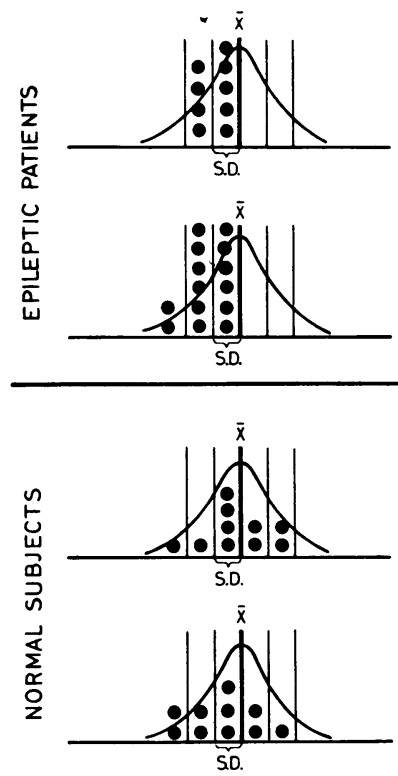

BONE MINERAL MASS DURING TREATMENT

Bone mineral mass $(\%$ of initial value)
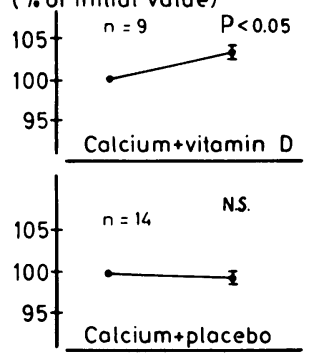

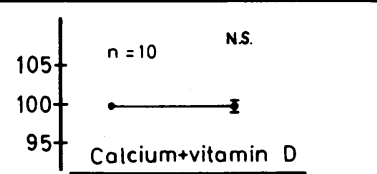

Bone mineral mass in 23 epileptic patients and in 20 normal subjects before and during treatment with calcium and vitamin $\mathrm{D}$ or calcium and placebo. Left. Initial value is compared with mean value and standard deviation in corresponding age and sex groups of normal persons. Right. Average bone mineral mass (as percentage of initial value) as a function of time during Not significant. 


\section{Results}

The bone mineral mass of the 23 epileptic patients and the 20 normal subjects compared with the values of other normal subjects matched for age and sex are shown in the chart. The initial values of all the 23 epileptic patients were below the corresponding normal mean value. In the group of epileptic patients treated with calcium lactate and vitamin $\mathrm{D}$ the mean bone mineral mass rose significantly. In the other three groups the mean bone mineral mass was unchanged (see chart).

\section{Discussion}

As previously found, the epileptic patients as a group had subnormal values (Berger and Munde, 1970; Linde et al., 1971; Christiansen et al., 1972), while the values in the normal subjects scatter around the mean.

This finding, and the unchanged values in both groups of normal subjects and in the placebo groups of epileptic patients, underlines that the method used is well reproducible (Christiansen and Rødbro, 1973). Our earlier findings (Christiansen et al., 1972), that bone mineral mass rises in epileptics during treatment with a small dose of vitamin $D$, are confirmed.

In this study we have found a 3\% increase in bone mineral mass, while we previously found an increase of nearly $7 \%$ (Christiansen et al., 1972). Two factors might contribute to this disparity. Firstly, the initial values of our nine patients were higher than the initial values of the patients in our earlier report. Secondly, the two studies were not planned in the same way, as the patients in the earlier study were treated with calcium lactate for one month before the treatment with vitamin $\mathrm{D}$.

Assuming that bone mineral mass in the forearm is representa- tive of total body calcium (Christiansen and Rødbro 1973), and that the mean value of normal young men corresponds to $1,000 \mathrm{~g}$ of total body calcium (Christiansen et al., 1972), it can be calculated that the mean total body calcium in the epileptic patients on vitamin D rose from 699 to $716 \mathrm{~g}$, corresponding to a mean positive calcium balance of $0.5 \mathrm{~g}$ per day during the trial.

The present study confirms that the epileptic patients, as a group, have subnormal values of bone mineral mass. Furthermore it shows that epileptic patients treated with vitamin D respond to this treatment, while normal subjects treated with vitamin $\mathrm{D}$ and epileptic patients treated with calcium lactate and placebo do not.

We thank Mrs. Birthe Jørgensen for valuable technical help, and the Danish Epilepsy Association for financial support.

\section{References}

Berger, G., and Munde, B. (1970). Deutsche Gesundheitswesen, 15, 1549. Cameron, J. R., Mazess, R. B., and Sorensen, J. A. (1968). Investigative Radiology, 3, 141

Christiansen, C., Kristensen, M., and Rodbro, P. (1972). British Medical fournal, 3, 738.

Christiansen, C., and Redbro, P. (1973). To be published.

Dent, C. E., Richens, A., Rowe, D. J. F., and Stamp, T. C. (1970). British

Medical fournal, 4, 69. (1971). British Medical fournal, 4, 202 .

Jensen, H., Christiansen, C., Lindbjerg, I. F., and Munck, O. (1972). Acta Radiologica, Suppl. No. 313, p. 214.

Kruse, R. (1968). Monatsschrift für Kinderheilkunde, 116, 378.

Larsen, N. E. (1971). Medical Laboratory Technology, 28, 377.

Linde, J., Hansen, J. M. Siersbaek-Nielsen, K., and Fuglsang-Frederiksen, V. (1971). Acta Neurologica Scandinavica, 47, 650.

Richens, A., and Rowe, D. J. F. (1970). British Medical fournal, 4, 73.

Schmid, F. (1967). Fortschritte der Medizin, 9, 381.

\section{Effects of Clonidine Withdrawal: Possible Mechanisms and Suggestions for Management}

\section{STEPHEN N. HUNYOR, LENNART HANSSON, TIMOTHY S. HARRISON, SIBLEY W. HOOBLER}

British Medical fournal, 1973, 2, 209-211

\section{Summary}

A severe rebound rise in blood pressure with agitation and insomnia had been noted in five patients when they had previously ceased clonidine (Catapres) This has been shown to be reproducible in these patients and to be associated with a significant increase in urinary catecholamine excretion. The blood pressure can be controlled and the symptoms alleviated promptly by alpha and beta adrenergic receptor blockade using intravenous phentolamine and propranolol.

Repatriation General Hospital, Sydney, N.S.W., Australia STEPHEN N. HUNYOR, M.B., M.R.A.C.P., Staff Specialist in Hyperten-
sion (Recipient of a Travel Grant of the National Heart Foundation of Australia)

Department of Internal Medicine, Sahlgrenska Hospital, Gothenburg, Sweden

LENNART HANSSON, M.D., Physician

University of Michigan Medical Center, Ann Arbor, Michigan, U.S.A.

TIMOTHY S. HARRISON, M.D., Professor of Surgery

SIBLEY W. HOOBLER, M.D., Professor of Internal Medicine, Head, Section of Hypertension

\section{Introduction}

Clonidine has found use as an antihypertensive agent in moderate (Smet et al., 1969; Parsons and Morledge, 1970) and severe (Raftos, 1969) hypertension, and when side effects such as orthostatic hypotension make adrenergic blocking agents impractical (Hoobler and Sagastume, 1971). It has a largely central site of action, and in rabbits it has been shown to have a central inhibitory action on adrenal catecholamine release (Shaw et al., 1971). A dose-related depression of urinary catecholamine levels has been shown in man (Hökfelt et al., 1970).

Sudden cessation of clonidine has been seen to result in severe rises in blood pressure (Hökfelt et al., 1969 1970; Hoobler, 1969) and a symptom complex of agitation, insomnia, and palpitations. The cause of the symptoms has been suggested to be a large catecholamine release, and some data after short-term therapy support this view (Hökfelt et al., 1970). Identification and further study of this phenomenon is reported.

\section{Materials and Methods}

Five patients were studied who had a previously well-documented blood pressure overshoot when clonidine (Catapres) 